Teresa Bielecka', Ewa Augustynowicz-Kopeć ${ }^{2}$ Paweł Gonerko³ ${ }^{3}$ Paweł Gruszczyński", Maria Korzeniewska-Koseła ${ }^{5}$, Maria Krasińska ${ }^{6}$, Katarzyna Krenke', Joanna Lange', Anna Pankowska ${ }^{7}$, Marek Popielarz ${ }^{8}$, Andrzej Pustkowski ${ }^{9}$, Joanna Stryczyńska-Kazubska ${ }^{10}$, Zbigniew Doniec $^{11}$

'Department of Pediatric Pneumonology and Allergy, Medical University of Warsaw, Poland

2Department of Microbiology, National Tuberculosis and Lung Diseases Research Institute, Warsaw, Poland

${ }^{3}$ I Department of Pediatrics, Allergy and Pulmonology, Szczecin, Poland

${ }^{4}$ Department of Microbiology of the Wielkopolska Center for Pulmonology and Thoracic Surgery of Eugenia and Janusz Zeyland, Poznań, Poland ${ }^{5}$ Department of Tuberculosis Epidemiology and Surveillance, National Tuberculosis and Lung Diseases Research Institute, Warsaw, Poland ${ }^{6}$ I Department of Pediatric Lung Diseases and Tuberculosis of Mazowsze Center for Lung Diseases and Tuberculosis Treatment, Otwock, Poland

'Department of Pediatric Respiratory Diseases, Center for Lung Diseases Treatment and Rehabilitation, Łódź, Poland

${ }^{8}$ Pediatric Pulmonology Clinic, University Hospital of Lord's Transfiguration, Poznań, Poland

${ }^{9}$ Department of Allergy and Lung Diseases, Children's Hospital Polanki, Gdańsk, Poland

${ }^{10}$ Department of Health Prophylaxis, Poznań University of Medical Sciences and Infectious Diseases Ward, Specialized Mother and Child Healthcare Centre in Poznań, Poland

"Department of Pneumonology, Tuberculosis and Lung Diseases Research Institute, Regional Department in Rabka-Zdrój, Poland Reviewers:

Prof. Anna Bręborowicz, Department of Pediatric Pneumonology, Allergy and Clinical Immunology University of Medical Sciences Poznań Poland

Prof. Grzegorz Lis, Department of Pediatrics, Chair of Pediatrics, Jagiellonian University Medical College, Krakow, Poland

All authors, except the first and the last one are listed in alphabetic order.

\title{
Recommendations for the management of tuberculosis in children — KOMPASS TB. Part 1: Tuberculosis prevention
}

The authors declare no financial disclosure.

\section{Abstract}

Since the second half of the $20^{\text {th }}$ century the incidence of tuberculosis has been declining in Poland. Despite this, current epidemiological data still support the need for the continued mass BCG vaccination in Poland in the near future. Apart from the protection against severe hematogenous forms of tuberculosis, vaccination lowers the risk of infection with Mycobacterium tuberculosis. Primary and acquired immunodeficiency, including immunity disorders associated with an ongoing treatment, are contraindications to BCG vaccination. The most common adverse effects following BCG vaccination are reactions at the site of injection and in regional lymph nodes, which usually does not require treatment.

Methods of tuberculosis prevention, particularly recommended in low-incidence countries, include: diagnostic investigations of patients who had contacts with pulmonary tuberculosis as well as an active detection and treatment of latent Mycobacterium tuberculosis infection. Latent tuberculosis infection can be identified on the basis of positive results of the tuberculin skin test or interferon-gamma release assays after the active disease has been ruled out. This condition does require prophylactic treatment.

Key words: BCG vaccination, tuberculosis contact investigation, latent tuberculosis infection

Adv Respir Med. 2018; 86: 149-157

The recommendations were developed on behalf of the Polish Society of Pediatric Pulmonology and National Consultant of Pediatric Pulmonology by the group of experts - TB Team.
The chairperson of the Team: Zbigniew Doniec - National Consultant of Pediatric Pulmonology.

The Team coordinator: Marek Popielarz

Address for correspondence: Katarzyna Krenke, e-mail: katarzyna.krenke@wum.edu.pl tel./fax +48 223179419

DOI: 10.5603/ARM.2018.0023

Received: 12.03 .2018

Copyright (C) 2018 PTChP

ISSN 2451-4934 
List of abbreviations:

\begin{tabular}{|c|c|}
\hline $\mathrm{AAP}-$ & American Academy of Pediatrics \\
\hline AFB - & acid fast bacilli \\
\hline 3CG - & baciilus Calmette-Guerin \\
\hline $\mathrm{CDC}-$ & $\begin{array}{l}\text { Centers for Disease Control } \\
\text { and Prevention }\end{array}$ \\
\hline EMB - & ethambutol \\
\hline HIV - & human immunodeficiency virus \\
\hline IGRA - & interferon gamma release assay \\
\hline INH - & isoniazid \\
\hline IUATLD - & $\begin{array}{l}\text { International Union Against } \\
\text { Tuberculosis and Lung Disease }\end{array}$ \\
\hline LTBI - & latent tuberculosis infection \\
\hline PZA - & pyrazinamide \\
\hline $\mathrm{RMP}-$ & rifampicin \\
\hline TBnet - & Tuberculosis Network \\
\hline \multicolumn{2}{|c|}{ TNF-alpha - tumor necrosis factor alpha } \\
\hline VAE - & vaccine adverse event \\
\hline WHO - & World Health Organization \\
\hline
\end{tabular}

Since the 1950s, the incidence of tuberculosis has been systematically declining in Poland [1]. In 2010, Poland has become a low-incidence country, where the role of tuberculosis prevention is particularly emphasized [2].

Basic tuberculosis prevention methods include the following:

- BCG vaccination;

- detection of latent tuberculosis infection (prophylactic and preventive treatment in risk groups);

- active tuberculosis detection in risk groups; - isolation and immediate treatment of infectious patients [2].

This article presents current guidelines concerning BCG vaccination, tuberculosis contact investigation as well as the diagnostic workup and preventive treatment of latent tuberculosis infection.

\section{BCG vaccination}

The BCG vaccine contains the attenuated live strain of bovine tuberculosis bacillus ( $M$. bovis). The vaccine has been named after its creators: Albert Calmette and Camille Guerin: $M$. bovis BCG (Bacillus Calmette- Guerin). Its implementation in the 1920s significantly decreased the incidence of severe hematogenous forms of tuberculosis (miliary tuberculosis and tuberculous meningitis) among infants and young children and reduced mortality associated with this disease [2, 3]. Current data indicate that BCG vaccination also lowers the risk of infection with Mycobacterium tuberculosis by approximately $19 \%$ and decreases the risk of progression to active tuberculosis by $71 \%$ [4-7].
According to the recommendations of the International Union Against Tuberculosis and Lung Diseases (IUATLD) [8], mass BCG vaccination is recommended in countries with sputum smear-positive pulmonary tuberculosis incidence equal to or greater than $5 / 100,000$ in the past 3 years. Despite a continuously improving situation in Poland, this value reached 7.37.1-6.8/100,000/year in the years 2014-2016, respectively [1].

As all other compulsory vaccination programs, BCG vaccination is mandatory, and any refusal should be reported in writing to the local public health inspector [9].

Contraindications to BCG vaccination (apart from those generally acknowledged for all vaccines) include the following [10, 11]:

- body mass $\leq 2,000 \mathrm{~g}$,

- congenital impairment of cell-mediated immunity or its suspicion,

- impairment of cell-mediated immunity in the family until their exclusion in the child,

- HIV infection (children of HIV-positive mothers can be vaccinated after HIV infection in the child has been ruled out),

- immunosuppression (e.g. steroid therapy, cytostatic drugs, treatment with TNF-alpha antagonists, radiotherapy),

- immunosuppressive treatment of the mother in the third trimester of gestation (vaccination should be postponed; in the case of treatment with TNF-alpha antagonists in the third trimester of pregnancy, the concentrations of the above mentioned drugs in the blood of infants have been detected up to the $6^{\text {th }}$, or even $12^{\text {th }}$ month of life) $[12,13]$,

- leukemia, lymphoma, disseminated cancer,

- generalized skin infections (until their regression),

- pregnancy,

- history of tuberculosis or infection with $M y$ cobacterium tuberculosis,

- ongoing anti-tuberculosis treatment (e.g. preventive).

\section{BCG vaccination program}

\section{General principles}

1. According to the WHO recommendations concerning countries where the epidemiological situation requires immunization, a BCG vaccine should be administered once in a lifetime, as soon as possible after birth [14].

2. According to the Polish preventive vaccination program, the BCG vaccine is obligatory 
up to 15 years of age if the child has not been vaccinated after birth [15].

3. As the lack of revaccination efficacy has been documented, it is no longer performed [16].

II. Detailed principles

1. Vaccination of neonates

- a vaccine can be administered after collecting the family history of congenital immunodeficiency.

- in children of HIV-positive mothers, vaccination should be postponed until the infection in the child has been ruled out.

- a vaccine is administered following the consent and in the presence of a parent or legal guardian.

2. Vaccination after the neonatal period

The procedures to be performed before vaccination:

- collect the family history of congenital immunodeficiency;

- basing on the history and physical examination, determine whether the child manifests typical signs of immunodeficiency (e.g. failure to thrive, recurring severe infections, chronic diarrhea, recurrent bacterial or fungal infections of the skin and mucous membranes, abscesses in the skin or organs) [17];

- basing on the history, estimate the risk of M. tuberculosis infection and determine whether a child has been or is in close contact with a tuberculosis patient or has a close contact with a person with chronic cough that has not been diagnosed;

- if the child has been or is in contact with an infected individual, tests have to be ordered in accordance with diagnostic principles presented below regarding the children who have come into contact with a tuberculosis patient;

- in the case of chronic coughing of an undiagnosed individual in the household settings, a plain chest radiograph for this person has to be ordered. If the results do not indicate tuberculosis, the child can be vaccinated. If the diagnosis of the coughing person is impossible, test the child with the TST and/or IGRA;

- when in doubt as to the risk of exposure to $M$. tuberculosis (e.g. in the school settings), inform the parents and the patient about a possibility to perform diagnostic tests (TST and/or IGRA) before BCG vaccination and about the risk of a local accelerated reaction in persons with tuberculosis infection [18];

- vaccinate after obtaining consent from the parent or de facto carer;

- up to the age of 6 years, vaccinate in the presence of the parent, legal guardian or de facto carer;

The diagnostic procedures before BCG vaccination of children suspected of having had a contact with a person with pulmonary tuberculosis are not dictated by vaccination safety but by epidemiological reasons, and their aim is to detect infected individuals early. There are no data about an increased risk of severe vaccination reactions after administering the vaccine to a patient infected with M. tuberculosis. However, the risk of the Koch's phenomenon, i.e. accelerated local reaction, is increased [18].

3. Immunization of children and adolescents without vaccination records (e.g. immigrants, refugees)

If vaccination records are not available, children up to the age of 15 should undergo BCG vaccination after a prior exclusion of infection, in accordance with the principles explained above.

\section{Normal local reaction after BCG vaccination}

A natural, local reaction after BCG vaccination involves redness appearing 2-3 weeks after the injection. Several weeks later, a nodule evolving to a pustule develops. It then ruptures to form a slight ulceration, and then crusts. The crust usually falls off after 8-10 weeks, leaving a slight scar measuring 6-8 $\mathrm{mm}$ in diameter [10]. The diameter of the pustule and ulceration should not exceed $10 \mathrm{~mm}$ in children vaccinated in the first year of life, and $20 \mathrm{~mm}$ in children vaccinated at an older age. A greater ulceration is considered a vaccine adverse event (VAE). The total healing time does not usually exceed 3 months [10]. The skin reaction at the site of BCG injection is usually accompanied by slightly enlarged (to $15 \mathrm{~mm}$ in diameter) lymph nodes (axillary, supraclavicular, subclavicular) [10].

\section{Adverse events after BCG vaccination}

The risk of VAEs is associated with the dosage, substrain (reactogenicity) of bacteria included in the vaccine and the manner of administration [5]. Differences between individual substrains have appeared as a result of passages in different laboratory settings over many years [19]. The Danish 
and French Pasteur substrains induce more adverse effects than the Tokyo and Glaxo substrains or the Brazilian Moreau substrain commonly used in Poland [5].

VAEs after BCG vaccine include local and nodal reactions (usually mild) as well as distant and generalized effects. The most severe VAEs (distant reactions and disseminated $M$. bovis infection after BCG vaccination) mainly develop in severely immunocompromised individuals.

Management of VAEs after BCG vaccination:

1. Local reactions

- Ulcerations and abscesses $>10 \mathrm{~mm}$ in diameter (in infants vaccinated in the first year of life) or $>20 \mathrm{~mm}$ (in children vaccinated later) are usually of self-limiting nature $[5,20]$. Observation and protection against superinfection are recommended.

- A local accelerated reaction (Koch's phenomenon) is an inflammatory reaction (redness, pustule and ulceration), which develops within 6 days after vaccination, usually after 24-48 hours. It occurs in persons with a tuberculosis infection [5], which necessitates a diagnostic process to confirm the infection (IGRA).

- A keloid, a raised nodular lesion of an irregular shape, at the BCG injection site is associated with pathological healing of the vaccination site. A consultation with a dermatologist or plastic surgeon is recommended [21].

2. Nodal reactions: enlarged ( $>15 \mathrm{~mm}$ ) regional lymph nodes (axillary, supraclavicular, subclavicular), on the side of vaccination.

The symptoms can develop within a week to even a dozen weeks after vaccination. In lymphadenopathy without accompanying purulent reactions, observation is sufficient. In suppurative lymphadenitis, the following are recommended:

— slight reactions: observation only,

- signs suggesting a fistula (fluctuation of the purulent content, skin thinning over the affected node): aspiration puncture and collection of the material for bacteriological examination for the concomitant infection. The puncture shortens the duration of the reaction, lowers the risk of spontaneous perforation and formation of a disfiguring scar [22-24].

Lymph node removal is not recommended as it is the last resort in persisting purulent inflammation.

3. Distant reactions

Distant reactions include:
- skin changes (ulcerating, lichenoid, nodular) beyond the injection site, erythema nodosum,

- iritis, conjunctivitis, optic neuritis,

- osteomyelitis [5].

\section{Osteomyelitis}

In Poland, it usually develops in individuals with cell-mediated immunity impairment. However, this complication is also observed in immunocompetent individuals [25] in countries where more reactogenic BCG substrains (Pasteur and Danish) are used [5].

It manifests as a bone defect, soft tissue edema, pain, restricted mobility and sparing of the affected area [25].

If this complication develops, the patient must be diagnosed with immunodeficiency (cell-mediated immunity disorders, severe immunodeficiency, HIV infection), and the etiology of infection must be confirmed (bacteriological tests for M. bovis $B C G$ in the referential tuberculosis laboratory). The treatment consists in combined anti-tuberculosis therapy without pyrazinamide (PZA) as $M$. bovis BCG is naturally resistant to this drug. Certain cases do require surgical intervention.

If multiple changes are observed, the patient should be diagnosed with systemic BCG dissemination.

Disseminated and systemic tuberculosis (BCG-itis) develops very rarely, usually in persons with a more severe impairment of cell-mediated immunity [26-28].

$B C G$-itis is manifested by general signs: fever or subfebrile temperature, failure to thrive, and distant tuberculosis changes beyond the injection site (in the skin, lymph nodes, lungs, liver, spleen, bones and soft tissues) [28]. When BCG-itis is suspected or there are distant reactions after BCG vaccination, the patient requires urgent diagnosis and treatment in a specialist center with diagnostic facilities enabling the identification of immunodeficiency (cell-mediated immunity deficits, severe complex immunodeficiency) and confirmation of the etiology of infection. The treatment involves first-line antituberculous agents excluding PZA: isoniazid (INH), rifampicin (RMP) and ethambutol (EMB). When the suspicion of BCG-itis is justified, treatment should be implemented instantaneously before bacteriological confirmation arrives. The prognosis is grave.

General guidelines for VAEs after BCG vaccination Obligatory procedures to be performed in all children with a VAE after BCG vaccination: 
- collect the family history of immunodeficiency,

- collect the history concerning the occurrence of the following symptoms: subfebrile temperature, appetite disorders, failure to thrive, apathy

- conduct a careful physical examination with particular attention paid to: skin reactions, peripheral lymph nodes, percussion signs over the lung fields as well as the size of the liver and spleen,

- assess complete blood count (with the emphasis on the absolute lymphocyte count),

- report VAEs to the local public health inspector.

Local and nodal reactions after BCG vaccination are not contraindications to the continuation of the remaining immunization programs in accordance with the Preventive Vaccination Program.

\section{Diagnostic workup for latent tuberculosis infection (LTBI)}

Latent tuberculosis infection can be identified basing on positive immunological tests: the tuberculin skin test and/or IGRA in the absence of clinical and radiological signs of tuberculosis.

As stated in the WHO guidelines from 2015, systematic screening for and proper treatment of LTBI in countries with annual incidence of tuberculosis $<100 / 100,000$ and with a good economic status should be conducted in:

- HIV-infected individuals,

- children and adults who have come into contact with a person with pulmonary tuberculosis,

- patients with planned treatment with TNF-alpha antagonists,

- organ or bone marrow transplant recipients,

- patients on dialysis,

- patients with silicosis.

Screening for LTBI should also be considered in:

- immigrants or refugees from countries with widespread tuberculosis,

- drug addicts,

- the homeless,

- prisoners,

- health care personnel [29].

The quoted WHO guidelines do not indicate the need for LTBI screening before the implementation of long-term immunosuppressive treatment (except for organ and bone marrow transplant recipients and candidates for TNF-alpha antagonist therapy). However, the opinion of the
Centers for Disease Control and Prevention (CDC), published in 2014, and of the American Academy of Pediatrics (Red Book 2015) are different. Their experts believe that long-term steroid or immunosuppressive therapy is an indication for LTBI tests [30, 31].

Some authors suggest that both steroid therapy and other immunosuppressants increase the risk of developing tuberculosis, but to a lower degree than TNF-alpha antagonists [32, 33].

It therefore seems justified to screen for LTBI before the implementation of any prolonged immunosuppressive treatment in children and especially in the following situations:

- in patients at a high risk of tuberculosis infection (positive family history of tuberculosis, origin from a country with high incidence of tuberculosis),

- if treatment with TNF-alpha antagonists is planned as the next step of therapy (this is because the TST and IGRA do not yield reliable outcomes after implementation of steroids or other immunomodulatory drugs). Before performing diagnostic tests for latent M. tuberculosis infection, typical signs of active tuberculosis must be ruled out (persisting cough, subfebrile temperature, weight loss or failure to thrive, night sweats, weakness, chest pain, hemoptysis). When active tuberculosis is suspected, the diagnostic process should be extended: a plain chest radiography and bacteriological tests for tuberculosis should be ordered.

In order to identify $M$. tuberculosis infection in accordance with the WHO guidelines, the tuberculin skin test or IGRA have to be performed.

According to the guidelines of the Tuberculosis Network (TBnet), both tests should be used simultaneously in children before the transplantation of solid organs and bone marrow and prior to treatment with TNF-alpha antagonists $[34,35]$.

Furthermore, due to a higher diagnostic sensitivity with both tests, their simultaneous application should be considered in the remaining patients with a high risk of developing tuberculosis (Table 1).

In children with a low risk of TB disease, TST or IGRA may be used.

When any of these tests are positive, a plain chest radiography should be performed. The presence of abnormalities compatible with tuberculosis forces an extended diagnostic process (including bacteriological tests for tuberculosis). Positive TST or IGRA (after ruling out active tuberculosis) is an indication for LTBI diagnosis and implementation of treatment. The aim of 


\section{Table 1. Factors that increase the risk of disease progres- sion after infection [36]}

Age $<5$ years
HIV infection or other congenital or acquired immunodeficiency
Disorders of the IFN- $\gamma-1 \mathrm{l}-12$ axis
Diabetes
Prolonged steroid therapy ( $>4$ weeks, prednisone $1 \mathrm{mg} / \mathrm{kg} \mathrm{per}$
day or $>15 \mathrm{mg}$ per day)
Immunosuppressive treatment, treatment with TNF- $\alpha$ antago-
nists
Hematologic diseases or diseases of the reticuloendothelial
system
Severe chronic renal failure
Chronic absorption disorders
Smoking
Underweight

LTBI treatment is to lower the risk of developing active tuberculosis. The following LTBI treatment regimens are proposed by WHO:

- INH once daily for 6 to 9 months,

- $\mathrm{INH}+$ RMP once daily for 3-4 months,

- RMP once daily for 3-4 months,

- $\mathrm{INH}+$ Rifapentine (not yet registered in Poland) once a week for 3 months.

There are no studies that would show the superiority of any of the 6- or 9-month INH therapy; WHO indicates equivalence of both regimens. The American Academy of Pediatrics suggests 9 months [31], while the 6-month regimen is recommended in Poland.

The dosage in LTBI is consistent with that used in the treatment of active tuberculosis:

- INH in children: $10 \mathrm{mg} / \mathrm{kg}(7-15 \mathrm{mg} / \mathrm{kg})$, in adults: $5 \mathrm{mg} / \mathrm{kg}$ (a maximum daily dose $300 \mathrm{mg}$ ),

- RMP in children: $10 \mathrm{mg} / \mathrm{kg}(10-20 \mathrm{mg} / \mathrm{kg})$, in adults: $10 \mathrm{mg} / \mathrm{kg}$ (a maximum daily dose $600 \mathrm{mg}$ ) [14, 29].

It must be remembered that only INH is registered for preventive treatment in Poland. Parental consent must be acquired for off-label use of RMP.

Prior to the initiation of treatment, baseline values of transaminases and bilirubin should be determined in:

- patients with an earlier or current liver disease,

- patients abusing alcohol,

- HIV-infected individuals,

- pregnant women or in the first 3 months after childbirth.

If baseline transaminase values are slightly increased, they must be systematically monitored during the treatment.
The remaining patients treated for LTBI should be regularly examined by a physician (clinical assessment, motivation to continue treatment, adverse effects monitoring). Patients and their parents should be familiar with potential adverse effects in order to report to the doctor immediately if they develop. The most common adverse effects are as follows: loss of appetite, nausea, vomiting, abdominal pain, fatigue, weakness, dark urine, pale stool and jaundice. If these symptoms develop and medical consultation is not possible, the treatment should be stopped.

\section{Tuberculosis contact investigation}

In accordance with the Act of 5 December 2008 on Prevention and Treatment of Infections and Infectious Diseases in Humans, individuals who come into contact with a tuberculosis patient should be under epidemiological surveillance, should undergo clinical examination and diagnostic tests or if needed, a preventive pharmacological treatment [9].

Contact with tuberculosis patient (necessitating diagnostic measures) is defined as:

- staying in one room with a sputum smear-positive individual (acid fast bacilli,$+ \mathrm{AFB}+$ ) for a total of 8 hours for up to 3 months before diagnosis;

- staying with a sputum smear-negative (AFB-) but sputum culture-positive individual for cumulative 40 hours for up to a month before diagnosis;

- a brief intensive face-to-face contact (e.g. during a laryngological examination or dental treatment) with a patient with pulmonary tuberculosis [33].

NOTE: The presence of a cavity on chest radiography or a cough increases the degree of infectiousness.

A tuberculosis patient stops being infectious approximately 2 weeks after the treatment implementation (when bacterial sensitivity to the treatment is presumed or confirmed, and the clinical improvement is noted).

Diagnostic tests should be conducted in individuals exposed to an index case of bacteriologically confirmed pulmonary tuberculosis (with positive sputum cultures or smears when the molecular tests have revealed that the bacteria do belong to the $M$. tuberculosis complex). In the case of individuals with a very high risk of tuberculosis (e.g. severely immunocompromised patients, neonates) coming into contact with a patient with tuberculosis which has not been 
Table 2. Time and manner of tuberculosis contact investigation

\begin{tabular}{|c|c|c|}
\hline & \multicolumn{2}{|c|}{ Time of examination } \\
\hline & $\begin{array}{c}\text { Urgent: }<1 \text { week after diagnosis or as soon as } \\
\text { possible }\end{array}$ & $\begin{array}{l}8 \text { weeks after the last contact with } \\
\text { the index case during the period of } \\
\text { infectiousness }\end{array}$ \\
\hline $\begin{array}{l}\text { Children from the close contact group } \\
\text { at high risk of tuberculosis }{ }^{2} \text { or with clini- } \\
\text { cal signs of tuberculosis }\end{array}$ & TST, IGRA and chest radiography & TST, IGRA and chest radiography \\
\hline $\begin{array}{l}\text { The remaining children from the close } \\
\text { contact group }\end{array}$ & TST or IGRA ${ }^{3}$ & TST or IGRA \\
\hline $\begin{array}{l}\text { Children from the casual contact group }{ }^{4} \\
\text { at high risk of tuberculosis }\end{array}$ & TST, IGRA and chest radiography & TST and IGRA \\
\hline $\begin{array}{l}\text { The remaining children from the casual } \\
\text { contact group }\end{array}$ & - & $\begin{array}{l}\text { If infection transmission has been } \\
\text { confirmed in children from the close } \\
\text { contact group: TST or IGRA }\end{array}$ \\
\hline $\begin{array}{l}\text { Children from the community contact } \\
\text { group }\end{array}$ & - & $\begin{array}{l}\text { If significant }{ }^{6} \text { infection transmission has } \\
\text { been confirmed in children from the ca- } \\
\text { sual contact group: TST and/or IGRA }\end{array}$ \\
\hline $\begin{array}{l}{ }^{1} \text { Close contact: household or long-term contact in } \\
{ }^{2} \text { High risk of tuberculosis: see Table } 1 . \\
{ }^{3} \text { Urgent examinations are indicated only when trat } \\
{ }^{4} \text { Casual contact: frequent contact e.g. frequent vis } \\
{ }^{5} \text { Community contact e.g. at school or sports club }\end{array}$ & $\begin{array}{l}\text { nfined space or close face-to-face contact, e.g. during medica } \\
\text { mission has been documented among children at high risk of } \\
\text { ors at home, class mates or those who spend free time togeth }\end{array}$ & $\begin{array}{l}\text { procedures (e.g. dental treatment) } \\
\text { veloping tuberculosis }\end{array}$ \\
\hline
\end{tabular}

bacteriologically confirmed, indications to a further diagnosis may be considered individually.

According to the European consensus, in the case of suspected tuberculosis with a negative sputum smear (and when the culture results have not yet arrived), the presence of a cavity in the chest radiography is an indication to pursue the source's contacts investigation (particularly children $<5$ years of age or other high-risk individuals with conditions listed in Table 1).

An overview of organization and timing of tuberculosis contact investigations is presented in Table 2.

\section{Urgent examinations}

Children with an increased risk of developing tuberculosis (Table 1) who have come into contact with an index case should be examined first as soon as possible.

This group should preferably undergo both TST and IGRA (if available) as well as a chest radiography. Children with clinical or radiological signs suggestive of tuberculosis should undergo bacteriological tests.

When conducting TST, the site of tuberculin injection must be documented in the patient's records (the first TST should be performed on the inner aspect of the left mid-forearm; so-called first field).
Table 3. Indications for chest radiography in tuberculosis contacts

Clinical sings compatible with tuberculosis:

persisting cough, night sweats, failure to thrive, subfebrile temperature, auscultatory changes over the lung fields

HIV infection, immunodeficiency either congenital or associated with ongoing treatment

Age $<5$ years

Positive TST or IGRA

If TST or IGRA are positive, but there are no clinical or radiological signs, LTBI should be identified and the prophylactic treatment started.

Indications for a chest radiography in tuberculosis contacts are listed in Table 3.

When in doubts about the results of the chest radiography (e.g. suspicion of lung hilar lymph nodes enlargement), contrast-enhanced computed tomography of the chest should be conducted.

When TST and IGRA are negative and there are no clinical or radiological signs in children with a high risk of developing tuberculosis $(<5$ years of age, HIV-positive, receiving immunosuppressive treatment), preventive treatment with INH should be initiated.

The remaining children from the close contact group may also be optionally tested urgently. This is even more justified with confirmed transmission 
Table 4. The criteria for interpretation of a positive TST in investigated tuberculosis contacts (according to the European consensus)

\begin{tabular}{|c|c|c|c|}
\hline $\begin{array}{l}\text { Risk of tuberculosis } \\
\text { infection }\end{array}$ & $\begin{array}{l}\text { Factors affecting the risk of tuber- } \\
\text { culosis }\end{array}$ & $\begin{array}{l}\text { Non-BCG-vaccinated or BCG-vac- } \\
\text { cinated in the first year of life }\end{array}$ & $\begin{array}{l}\text { BCG-vaccinated after the first } \\
\text { year of life }\end{array}$ \\
\hline \multirow{4}{*}{$\begin{array}{l}\text { High (close contact } \\
\text { with a smear-positive } \\
\text { tuberculosis patient) }\end{array}$} & Immunocompetent & $\geq 10 \mathrm{~mm}$ & $\geq 15 \mathrm{~mm}$ \\
\hline & Immunocompromised & & \\
\hline & HIV infection & $\begin{array}{l}\text { Negative TST does not exclude } \\
\text { infection }\end{array}$ & $\begin{array}{l}\text { Negative TST does not exclude } \\
\text { infection }\end{array}$ \\
\hline & $\begin{array}{l}\text { Other factors of high risk of develo- } \\
\text { ping tuberculosis }\end{array}$ & $\geq 5 \mathrm{~mm}$ & $\geq 5 \mathrm{~mm}$ \\
\hline \multirow{4}{*}{$\begin{array}{l}\text { Low (other contacts } \\
\text { of tuberculosis pa- } \\
\text { tient) }\end{array}$} & Immunocompetent & $\geq 15 \mathrm{~mm}$ & TST not recommended \\
\hline & Immunocompromised & & \\
\hline & HIV infection & $\begin{array}{l}\text { Negative TST does not exclude } \\
\text { infection }\end{array}$ & $\begin{array}{l}\text { Negative TST does not exclude } \\
\text { infection }\end{array}$ \\
\hline & $\begin{array}{l}\text { Other factors of increased risk of } \\
\text { developing tuberculosis }\end{array}$ & $\geq 10 \mathrm{~mm}$ & $\geq 10 \mathrm{~mm}$ \\
\hline
\end{tabular}

among children with a high risk evaluated in the first place. Preventive treatment is not applied in immunocompetent children $>5$ years of age.

\section{Tests after an 8-week window}

Eight weeks after the last contact with an infectious individual, children previously examined urgently are re-examined, and all other contact children undergo tests.

Children with a high risk of developing tuberculosis undergo repeated TST, IGRA and a chest radiography.

When conducting a repeated tuberculin skin test within a short period of time, one must remember about changing the site of tuberculin injection (the second field: the inner aspect of the right mid-forearm) so as to reduce the risk of a booster effect, which results in an increased skin reaction. If there are radiological abnormalities or clinical signs, bacteriological tests should be conducted.

In children $>6$ months of age and $<5$ years of age treated preventively with INH, the treatment can be discontinued once the repeated TST and IGRA are negative and there are no clinical/ /radiological signs of the disease.

In children $<6$ months of age, HIV-infected or severely immunosuppressed, the preventive treatment with INH should be continued for 6 months even when TST and IGRA are negative.

TST or IGRA, and optionally also a chest radiography, should be conducted in children $>5$ years of age without additional risk factors of tuberculosis. If there are radiological abnormal- ities or clinical signs, bacteriological tests must be ordered.

If TST or IGRA are positive but there are no clinical or radiological signs of tuberculosis, LTBI should be identified and preventive treatment started (according to regimens presented above).

The criteria for interpretation of a positive TST in investigated tuberculosis contacts, as provided in the European consensus, are shown in Table 4.

As for pulmonary tuberculosis contacts in the school settings, screening should start with high-risk individuals and those who have had the closest and the longest contact with the patient (e.g. class mates, so-called "first circle"). If the infection transmission is confirmed in the first circle, diagnostic tests should also be conducted in occasional contacts ("second circle").

\section{Acknowledgments}

The authors wish to thank Prof. Ewa Bernatowska for her motivation to prepare the guidelines, and support in terms of content.

\section{Conflict of interest}

The authors declare no conflict of interest.

\section{References:}

1. Korzeniewska-Koseła M. Gruźlica w Polsce w 2016 r. Instytut Gruźlicy i Chorób Płuc, Warszawa 2017.

2. Diel R, Nienhaus A. Prevention of TB in areas of low incidence. Tuberculosis. 2012: 72-83, doi: 10.1183/1025448x.10022811.

3. Dara M, Acosta CD, Rusovich V, et al. WHO EURO Childhood Task Force members. Bacille Calmette-Guérin vaccination: the 
current situation in Europe. Eur Respir J. 2014; 43(1): 24-35, doi: 10.1183/09031936.00113413, indexed in Pubmed: 24381321.

4. Trunz BB, Fine P, Dye C. Effect of BCG vaccination on childhood tuberculous meningitis and miliary tuberculosis worldwide: a meta-analysis and assessment of cost-effectiveness. Lancet. 2006; 367(9517): 1173-1180, doi: 10.1016/S01406736(06)68507-3, indexed in Pubmed: 16616560.

5. http://www.who.int/vaccine_safety/initiative/tools/BCG_Vaccine_rates_information_sheet.pdf.

6. Colditz GA $\bar{A}$, Berkey CS, Mosteller F, et al. Efficacy of BCG vaccine in the prevention of tuberculosis. Meta-analysis of the published literature. JAMA. 1994; 271(9): 698-702, indexed in Pubmed: 8309034.

7. Roy A, Eisenhut M, Harris RJ, et al. Effect of BCG vaccination against Mycobacterium tuberculosis infection in children: systematic review and meta-analysis. BMJ. 2014; 349: g4643, indexed in Pubmed: 25097193.

8. Criteria for discontinuation of vaccination programmes using Bacille Calmette-Guerin (BCG) in countries with a low prevalence of tuberculosis. A statement of the International Union Against Tuberculosis and Lung Disease. Tuber Lung Dis. 1994; 75(3): 179-180, doi: 10.1016/0962-8479(94)90003-5, indexed in Pubmed: 7919307.

9. Dziennik Ustaw $2008 \mathrm{nr} 234$ poz. 1570. http://isap.sejm.gov.pl/ DetailsServlet?id=WDU20082341570.

10. https://baza-lekow.com.pl/szczepionka-przeciwgruzlicza-bcg-10/\#CHAR

11. https://lekomanprod.blob.core.windows.net/product-documents/doc21971/bcg-szczepionka-ssi-dokument.pdf.

12. Cheent K, Nolan J, Shariq S, et al. Case Report: Fatal case of disseminated BCG infection in an infant born to a mother taking infliximab for Crohn's disease. J Crohns Colitis. 2010; 4(5): 603-605, doi: 10.1016/j.crohns.2010.05.001, indexed in Pubmed: 21122568.

13. Esteve-Solé A, Deyà-Martínez À, Teixidó I, et al. Immunological Changes in Blood of Newborns Exposed to Anti-TNF- $\alpha$ during Pregnancy. Front Immunol. 2017; 8: 1123, doi: 10.3389/ fimmu.2017.01123, indexed in Pubmed: 28983301.

14. WHO, Guidance for national tuberculosis programmes on the management of tuberculosis in children Second Edition. http:// www.who.int/tb/publications/childtb guidelines/en/.

15. https://gis.gov.pl/images/pso_2018_r_.pdf.

16. Roth AE, Benn CS, Ravn H, et al. Effect of revaccination with BCG in early childhood on mortality: randomised trial in Guinea-Bissau. BMJ. 2010; 340: c671, indexed in Pubmed: 20231251.

17. Pietrucha B, Heropolitańska-Pliszka E, Klaudel-Dreszler M, et al. Wybrane zagadnienia z immunologii klinicznej - niedobory przeciwciał i niedobory komórkowe (część I). Pediatria Polska. 2011; 86(5): 548-558, doi: 10.1016/s0031-3939(11)70532-7.

18. Tebruegge M, Buonsenso D, Brinkmann F, et al. Paediatric Tuberculosis Network European Trials Group (ptbnet). Tuberculous dactylitis--an easily missed diagnosis. Eur J Clin Microbiol Infect Dis. 2011; 30(11): 1303-1310, doi: 10.1007/ s10096-011-1239-5, indexed in Pubmed: 21491177.

19. Oettinger T, Jørgensen M, Ladefoged A, et al. Development of the Mycobacterium bovis BCG vaccine: review of the historical and biochemical evidence for a genealogical tree. Tuber Lung Dis. 1999; 79(4): 243-250, doi: 10.1054/tuld.1999.0206, indexed in Pubmed: 10692993.

20. Venkataraman A, Yusuff M, Liebeschuetz S, et al. Management and outcome of Bacille Calmette-Guérin vaccine adverse reactions. Vaccine. 2015; 33(41): 5470-5474, doi: 10.1016/j. vaccine.2015.07.103, indexed in Pubmed: 26275478.
21. Sanders R, Dickson MG. BCG vaccination scars: an avoidable problem? Br Med J (Clin Res Ed). 1982; 285(6356): 1679-1680, indexed in Pubmed: 6816328.

22. Cuello-García CA, Pérez-Gaxiola G, Jiménez Gutiérrez C. Treating BCG-induced disease in children. Cochrane Database Syst Rev. 2013(1): CD008300, doi: 10.1002/14651858.CD008300. pub2, indexed in Pubmed: 23440826.

23. Pal S, Chakarabarti S, Phukan JP, et al. Role of needle aspiration in diagnosis and management of suppurative bacille calmette-guerin adenitis: an institutional study of 30 cases. J Lab Physicians. 2015; 7(1): 21-25, doi: 10.4103/09742727.154782, indexed in Pubmed: 25949055.

24. Hang WM, Kwan YW, Leung CW. Management of Bacillus Calmette-Guérin Lymphadenitis. HK J Paediatr. 2011; 16: 8594, doi: $10.1007 /$ springerreference 37813.

25. Lin WL, Chiu NC, Lee PH, et al. Management of Bacillus Calmette-Guérin osteomyelitis/osteitis in immunocompetent children-A systematic review. Vaccine. 2015; 33(36): 43914397, doi: 10.1016/j.vaccine.2015.07.039, indexed in Pubmed: 26212004.

26. Al-Mousa H. An infant with disseminated bacillus Calmette-Guerin infection (BCGitis). International Journal of Pediatrics and Adolescent Medicine. 2014; 1(2): 89-92, doi: 10.1016/j.ijpam.2014.11.005.

27. Antaya RJ, Gardner ES, Bettencourt MS, et al. Cutaneous complications of BCG vaccination in infants with immune disorders: two cases and a review of the literature. Pediatr Dermatol. 2001; 18(3): 205-209, indexed in Pubmed: 11437999.

28. Bernatowska E, Wolska-Kuśnierz B, Pac M, et al. Risk of BCG infection in primary immunodeficiency children. Proposal of diagnostic, prophylactic and therapeutic guidelines for disseminated BCG based on experience in the Department of Immunology, Children's Memorial Health Institute in Warsaw between 1980-2006. CentrEur J Immunol. 2007; 32: 221-225.

29. WHO Guidelines on the management of latent tuberculosis infection. WHO/HTM/TB/2015.01. http://www.who.int/tb/publications/ltbi_document_page/en/.

30. https://www.cdc.gov/tb/publications/ltbi/default.htm.

31. Kimberlin DW, Brady MT, Jackson MA, Long SS. American Academy of Pediatrics. Red Book: 2015 Report of the Committee on Infectious Diseases. 30th ed. Tuberculosis. Elk Grove Village 2015: 805-831.

32. Toruner M, Loftus EV, Harmsen WS, et al. Risk factors for opportunistic infections in patients with inflammatory bowel disease. Gastroenterology. 2008; 134(4): 929-936, doi: 10.1053/j. gastro.2008.01.012, indexed in Pubmed: 18294633.

33. Erkens CGM, Kamphorst M, Abubakar I, et al. Tuberculosis contact investigation in low prevalence countries: a European consensus. Eur Respir J. 2010; 36(4): 925-949, doi: 10.1183/09031936.00201609, indexed in Pubmed: 20889463.

34. Bumbacea D, Arend SM, Eyuboglu F, et al. The risk of tuberculosis in transplant candidates and recipients: a TBNET consensus statement. Eur Respir J. 2012; 40(4): 990-1013, doi: 10.1183/09031936.00000712, indexed in Pubmed: 22496318.

35. Solovic I, Sester M, Gomez-Reino JJ, et al. The risk of tuberculosis related to tumour necrosis factor antagonist therapies: a TBNET consensus statement. Eur Respir J. 2010; 36(5): 1185-1206, doi: 10.1183/09031936.00028510, indexed in Pubmed: 20530046.

36. Lancella L, Vecchio A, Chiappini E, et al. How to manage children who have come into contact with patients affected by tuberculosis. Journal of Clinical Tuberculosis and Other Mycobacterial Diseases. 2015; 1: 1-12, doi: 10.1016/j.jctube.2015.07.002. 